\title{
Challenges for organizational structure and design as a result of digitalization and cybersecurity
}

\author{
Narcisa Roxana Moşteanu \\ Department of Business Administration \\ American University of Malta, Malta
}

\begin{abstract}
Keywords
Digitalization, digital disaster, cybersecurity, organizational structure and design.
\end{abstract}

\begin{abstract}
Fintech technologies and digital systems transformation have become the most commonly used words in the last decade, with a direct impact on any organizational structure and design. Rearranging values change the business process. The present paper emphasizes that, in order to remain competitive and achieve market longevity, organizational structures must keep up with the digital transformation and implementation of new security systems in order to face cyberattacks exposure. Protecting data (e.g. financial and clients), improving the performance but also the survival of institutions is related to the adoption of innovation and the adoption of digital changes into organizational culture and redesign its structure. The article aims to show how new technologies together with their requirements can improve the organizational structure to face actual challenges, such cyberattacks; and how digital transformation and the adoption of new technologies have changed the approach of the job requirements on the global level. In order to underline the necessity of amendments of the business process, the author redesigns an organizational structure taking into consideration new technologies challenges and implementations of new functions. The change proposed for redesigning the organizational structure is based on balancing the differentiation and integration among specialized departments, to avoid operational risks.
\end{abstract}

\section{Introduction}

Successful organizational change requires that you use all of the ingredients, inject lots of care and passion, and don't take any shortcuts (McCalman and Potter, 2015). The new technologies and the informational reforms bring to the society new managerial demands for the efficient management of the necessary changes in the business and social environment. As businesses use more and more internet and computer networks, daily activities are dramatically being reshaped. Businesses, employees become better informed and can work more efficiently, yet there is uncertainty about data and job place about security at the same time. The digitalization and big data reveal both the opportunities and dangers for workers and businesses in the digital age. New digital technologies shape organizational design and cultural change (Jacobs and Yudken, 2003).

An organization is a tool people use to coordinate their actions to obtain something they desire or value - that is, to achieve their goals (Jones, 2013). The actual development of the business approach, though FinTech has a direct impact on jobs and organizational structure, and concludes that the digital systems ultimately reduce transaction costs thereby aiding profit-making, and also assists workers, consumers, and citizens in challenging business practices, then, at the same time, it may expose data to cyberattacks.

Digital solutions and new technologies offer great potential to overcome massive development challenges and can contribute to achieving the goal of universal access to all business services (Moshirian, 2011). Digitization and digital business promise a universe of applications and digitalized assets that are expected to work together to allow rapid development of new capabilities that will give a competitive advantage (Moşteanu, 2019a). To remain competitive and achieve longevity in the market, businesses must keep up with the digital transformation (Moşteanu and Modarress Fathi, 2020). Using big data and digital systems, through the internet and IT devices may expose the business secrecy to cyber-attacks. Dispute cyberattacks become the first threat for business, which usually come with financial repercussions. Many companies from around the world started to use Artificial Intelligence in their business process because it helps companies to reduce operating costs, boost productivity and deliver the 
ultimate customer experience. Artificial Intelligence is one of these game-changing tools for business. However, other companies are still shy in integrating and using Artificial Intelligence and new technologies for various reasons, mainly due to lack of knowledge, and/or lack of resources (Marketingcharts, 2017; Moşteanu 2020a). Cyberattacks are usually aimed at accessing, changing, or destroying sensitive information; extorting money from users; or interrupting normal business processes (Moşteanu 2020b). The present work paper seeks to show how new technologies together with their requirements can improve the organizational structure to face actual challenges.

\section{Literature review}

The survival of businesses is connected with the adoption of innovation, and embracing digital changes, to improve the efficiency and the performance within the organization (Scardovi, 2017). The reconstruction of organizations design using actual financial technologies imply new educational specializations and developing new skills and competences to fulfill de challenges of different and new job requirements. This requires promoting a stable business climate, offering an efficient infrastructure, using the newest technologies, which become the greatest conditions to welcome investments, employing actual technologies to boost economic development (Moşteanu, 2019b). Digital database technologies facilitate the generation, calculation, and circulation of the data required to (Williamson, 2016) develop new educational curriculum to prepare people for successful employment in a digitalized era. Digital systems are becoming more and more used, representing a much faster, cheaper, and safer way when it comes to financial transactions. Access to modern telecommunications systems is a priority in all countries around the world, as in their evolution, financial and banking systems implement, use, and encourage online services for domestic and international financial transfers (Moşteanu and Faccia, 2020). Digitization and digital transformation have become the most used words in the last decade, but especially in recent years. There is an excess of definitions of this term, used to describe the offline-to-online migration of commercial operations and businesses, including those found in many published research works (Moşteanu, 2020c). All of this comes to help businesses to develop their activity and to improve their productivity. However, digital exposure may lead to digital disaster or digital disruption, which requires cybersecurity (Moşteanu 2020e, f). Digital disruption is defined by Oxford College as a transformation that is caused by emerging digital technologies and business models. The digital innovative new technologies and models can impact the value of existing products and services offered in the industry. Therefore, the term disruption is used, as the emergence of these new digital products/services/businesses disrupts the current market and causes the need for re-evaluation (Oxford College of Marketing, 2016).

Cyber security, a concept that arrived on the post-Cold War agenda in response to a mixture of technological innovations and changing geopolitical conditions (Hansen and Nissenbaum, 2009). Over the year, due to the continue improving the technologies, hacking become more complicated. New and new cases of cyber-attack risen, such as Snowden $\mathcal{E}$ The NSA, 2013 (a former CIA copied and leaked classified information from NSA); Yahoo 2013-2014 (hackers broke into Yahoo, jeopardizing the accounts and personal information of all their 3 million users); WannaCry, 2017 (known as ransomworm - targeted computers running the Microsoft Windows operating systems and demanded ransom payments in the Bitcoin cryptocurrency), (Murphey, 2019). All this was possible because, while there are significant advances in information technology and infrastructure which offer new opportunities, cyberspace is still far from completely secured. Currently, in many cases, the employed security solutions are ad hoc and lack a quantitative decision framework (Shiva, et.al., 2010).

\section{Research methodology}

The present work paper is exploratory research, based on investigative techniques. It is fundamental and qualitative research, which aims to identify the main impediments encountered in digitizing the activity of institutions, as well as the necessity of adapting the organizational structure and speed of adapting the workforce to the new requirements regarding the provision of innovative administrative and products and services through digital technology and cybersecurity systems. The paper presents how organizations redesign their structures to compete with new digital technologies. The research paper uses macroeconomic indicators from different regions of Europe, related to the new developments of the labor market, economic and social progress trends. 


\section{Findings}

An organization's environment is a complex network of changing pressures and forces that affect the way it operates (Jones, 2013). Environment is the one which leads to and entrepreneurship or to a change in organizational design. A business organizational structure is affected directly by the specific and general environments. Specific environment deals with customers' desires and needs, with competitors' activities, supply chain management, and governmental rules and regulations. General environment deals with socio-economic policies, cultural and demographic forces, international movements, and technological forces. Technological forces, such as the development of new production techniques, new information-processing equipment, use of big data and artificial intelligence, cloud services, and hyper-processing systems influence many aspects of organizations' operations. The use of computerized manufacturing technology can increase productivity. Similarly, investment in advanced research and development activities influences how organizations interact with each other and how they design their structures. Digitalization transform the business operations in at least five ways (Maruti TechLabs, 2019): risk assessment; fraud detection and management; financial advisory services; trading; and managing finance. Figure no.1 presents how FinTech is improving a financial institution's activity. Artificial Intelligence allows the automation of domains that require intelligent analysis and clear thinking. One of the biggest challenges faced by large banks, insurance is that large volumes of their historical data are stored in paper documents rather than in digital spaces. Machine learning models are necessarily trained on digital data, so financial institutions have to ensure that they digitize old documents before hiring scientists to build digital solutions or to purchase Artificial Intelligence software from vendors (Azuly, 2019).

Figure no.1: Artificial Intelligence used in different types of businesses. (Moşteanu, 2019c)

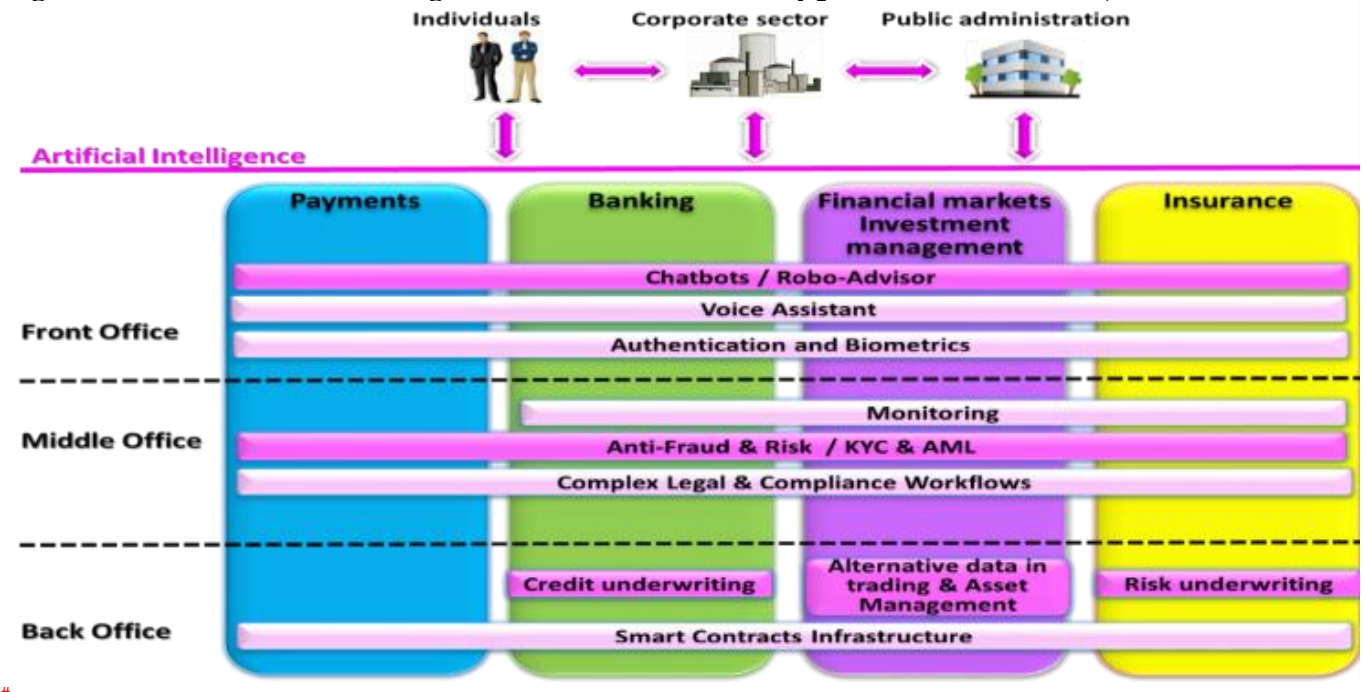

Institutions are based on and rely on computers and experts to determine future models of the market. Transactions and investments depend on the ability to accurately predict the future. The machines are excellent because they can shorten a huge amount of data in a short time. FinTech is beginning to be implemented in businesses by running behind-the-scenes algorithms able of processing huge amounts of information (big data) which would otherwise be either too large to comprehend by the human mind or too mundane. This international transfer of technology has important implications for an organization's competitive advantage. Organizations must be able to learn about and have access to technological developments abroad that might provide a low-cost or differentiation advantage. New skills are required, new departments or functions will be created, and, in the end, the organizational structure will be redesign. Digitalization becomes an integrated part of any organization and is taken as a new investment in, advanced technology and business models to engage digital customers more effectively at every touchpoint in the customer experience lifecycle (Solis, et.al., 2014).

As we presented earlier, once with new digital technologies, cyberattacks appeared. Currently, a cyberattack can have many faces (research found at least 25): phishing; ransomware; malware; social 
engineering; brute force; man-in-the middle; Rootkit, DoS/DDoS, Botnet, Evil Twins, Keylogger, RAT, AdWare, Malvertising, Spam, Spyware, Virus, Worm, Trojan, Vishing, Watering Hole, Backdoor, Spoofing, Honeypot, Cyber- espionage. With the advances in information technology, criminals are using cyberspace to commit numerous cyber-crimes (Moşteanu 2020a; Moşteanu, et.al., 2020a). Cyber infrastructures are highly vulnerable to intrusions and other threats. Physical devices and human intervention are not sufficient for monitoring and protection of these infrastructures; hence, there is a need for more sophisticated cyber defense systems that need to be flexible, adaptable and robust, and able to detect a wide variety of threats and make intelligent real-time decisions (Dilek, et.al., 2015). Cyber security comes as the practice of protecting systems, networks, and programs from digital attacks, which access, change, or destroy sensitive information; extorting money from users; or interrupting normal business processes (CISCO, 2019).

Everything becomes digital or cyber: space, tools, literacy, solutions, data systems, education, generation, and types of markets. Institutional reforms in labor relations are carried out in the digital economy both in the content and in the form (Moşteanu, et.al., 2020b, c). New technologies restructure subject-object economic relations and change qualitatively a business approach based on special algorithms application (Vovchenko, et.al., 2017). In this respect, organizations are better to redesign their structure, work processes, and services provided in order to face the challenges of customers - workforce. Figure no. 2 presents a possible solution to redesign an organizational structure in the banking industry.

Figure no.2: Redesign the organizational structure

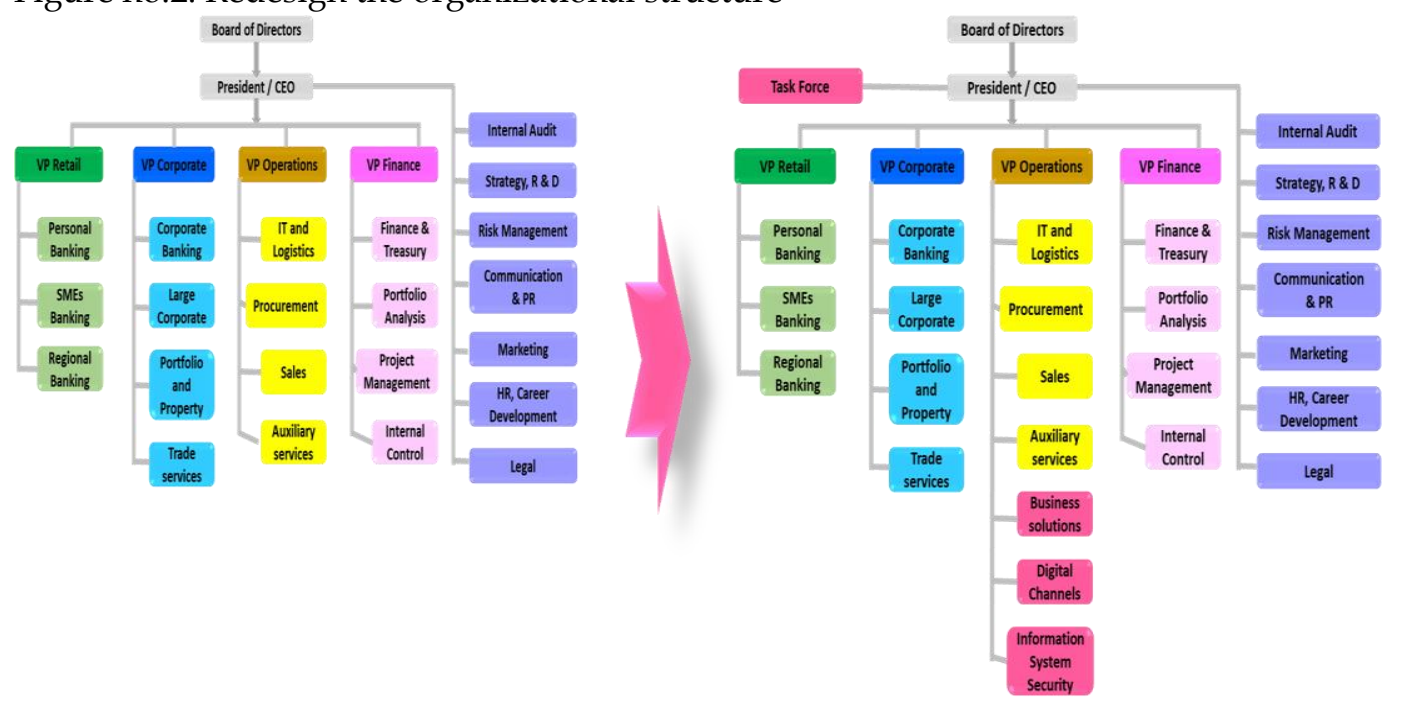

Before

After integrating cyber security departments

Organizational structure is based on a system of interlocking roles, and the relationship of one role to another is defined by task-related skills. Figure no. 2 presents how an organization is redesigning its structure taking into consideration new technologies' challenges and implementations of new functions. Digitalization requires to redesign the organizational structure by balancing the differentiation and integration among specialized departments. In order to integrate FinTech and cybersecurity, new departments were created along with new job skills requirements. Also, a task force team was established in order to ensure the integration approach, between new IT requirements and regular business departments. Task-force teams are formed from managers with different specializations. As an organization increases in complexity, more than two departments may need to work together to solve common problems. Increasing an organization's ability to serve its business effectively, may require, as an example, input from IT, legal, HR, marketing, strategy, and R\&D. The solution commonly takes the form of a task force, a temporary committee set up to handle a specific problem. Moreover, even we tend to more organic business structures than mechanic ones, in order to ensure a proper cybersecurity system, a standardized approach (standard operation system) when it comes to big data protection, and internet communication is more than necessary. 
Digitalization improves any organization's activities, but also expose it to different cyber-attacks. From this perspective only redesigning activities and add new functions and departments, populated with people with dedicated skills is not enough. A certain budget is better to accompany all these changes. A study conducted by Deloitte (2019) which polled 500 Chief-level executives who oversee cybersecurity at companies with at least $\$ 500$ million in annual revenue, it revealed that from total IT and risk management budget, only $56 \%$ from respondents specified that only a $10 \%$ budget is dedicated to digital transformation (figure no.3), and out of this 10\% budget for digital transformation only $16 \%$ is dedicated to data security, $14 \%$ is dedicated to cyber transformation and another $14 \%$ to infrastructure security, the rest of the budget is dedicated to other integrated application and security infrastructure (figure no.4).

Figure no.3: Cyber budget allocation (\%) to $\quad$ Figure no.4: Organization's cyber budget digital transformation

$$
\text { Total participants }
$$
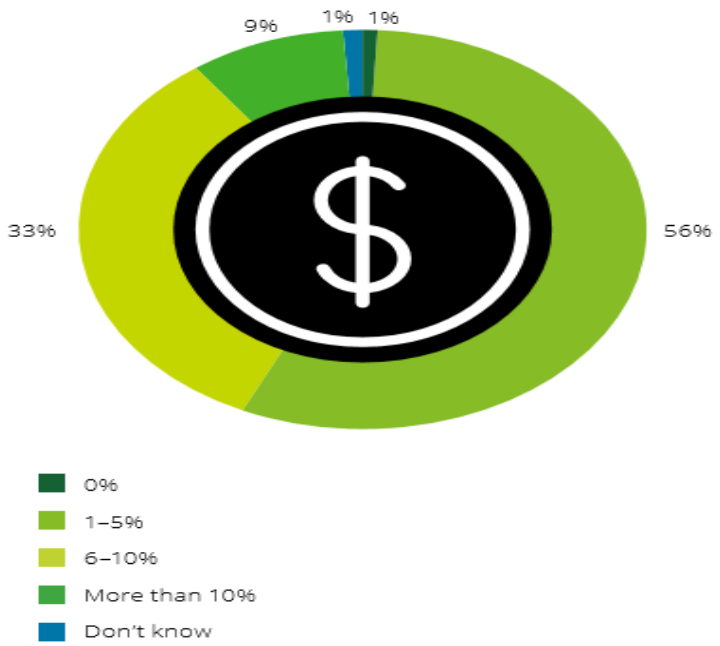

Total participants
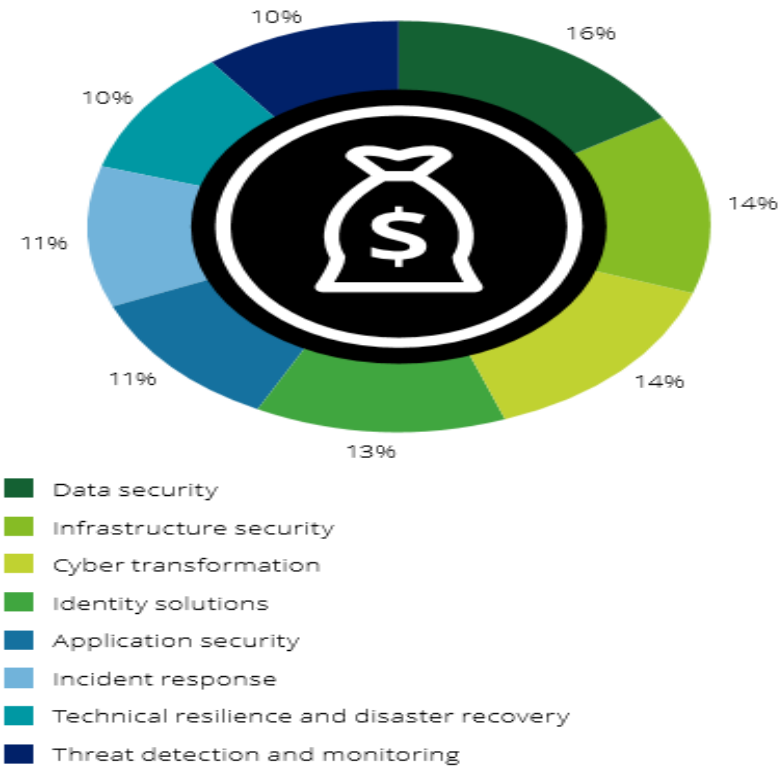

To tackle the digital skills gap, significant investments are needed. In the current European Union budget, the Commission proposes coherent and comprehensive support for building up the digital skills needed to support reskilling and upskilling in Europe for a successful digital transformation. Digital 
Europe Program with a budget of $€ 700$ million will expand the digital talent pool with around 256,000 people who will be able to deploy the latest technology in business throughout Europe. In order to develop The Digital Europe Program, European Commission conducted research for the deployment of innovative digital technologies in five key areas: Supercomputing; Artificial Intelligence; Cybersecurity; advanced digital skills; and ensuring a wide use of these digital technologies across the economy and society in line with Europe's ambitious sustainability goals and values.

Figure no.5. Respondents per country of origin (European Commission, 2019)

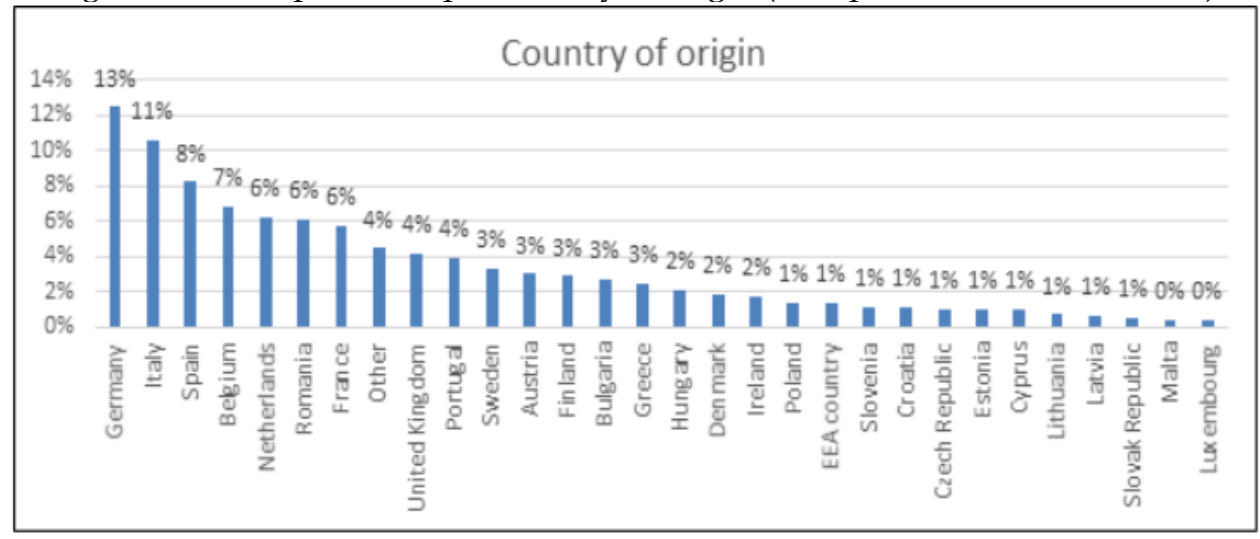

To see the real financial implications and the number of new job structures, the survey was focused on (European Commission, 2020): better understanding the potential level of demand for the different activities that are proposed under Digital Europe; understanding stakeholders' opinions and interests with regards to the priorities set out for the strategic objectives of the digitalization; and, obtaining the information needed in view of implementation choices and of timely preparation of the work programs to face the challenges of the digital era. There were 960 respondents from all 28 European Union countries. 326 replies from European Union citizens, 171 from companies and business organizations, 41 from business associations, 124 from public sector entities, and 163 from academic and research institutions as well as several other groups. The largest number of responses came from Germany $(13 \%)$, Italy (11\%), Spain (8\%), Belgium (7\%), the Netherlands (7\%), Romania $(6 \%)$ and France $(6 \%)$ totaling $56 \%$ of responses.

Findings show solid support for the main concern set out in the Digital Europe Program with more than $80 \%$ of the respondents approving the priorities across the main objectives. On the question Do you agree that the European Union should support member states in improving for the deployment of innovative digital technologies? For Supercomputing: 59\% completely agree and 24\% partially agree; for Artificial Intelligence - $64 \%$ completely agree and $24 \%$ partially agree; for Cybersecurity - $64 \%$ completely agree and $22 \%$ partially agree; for Advanced digital skills - 74\% completely agree and $16 \%$ partially agree, and for ensuring a wide use of these digital technologies across the economy and society: - $62 \%$ completely agree and $24 \%$ partially agree. These responses transmit a tangible interest of citizens for their job stability, business for their continuity, academics, and researchers for new practical approach of the digital changes. Respondents were also asked to indicate how important they viewed European Union support for a range of areas where the new digital technologies could be deployed with a high impact. The results indicate a very strong support for EU support for digital technologies and their use in creating a clean planet (70.5\% - very important), the digital transformation of learning and education (62.5\% - very important) and a more trustful and safer internet (54.9\% - very important). On the other hand, the responses indicate less support for the uptake of the blockchain (32.1\% - particularly important).

\section{Conclusions}

Digitalization has come into wide use in contemporary business media to signify the transformational or disruptive implications of digital technologies for businesses (Nambisan, et.al., 2019) (new business models, new types of products and services, new types of customer experiences) (Boulton, 2018; Boutetiere, Reich, 2018) and more broadly, to indicate how existing companies may need to radically transform themselves to succeed in the emerging digital world (McAfee, Brynjolfsson, 2017; Brynjolfsson, 
2011; Rogers, 2016; Venkatraman, 2017). Digital transformation affects all businesses; however, new enterprises are giving more attention to offering new digital solutions (Ayandibu, Houghton, 2017).

Today's cyber leaders are focused on digital transformation as an important strategy to achieve greater efficiencies while also better protecting the business (Deloitte, 2019). That sets attention to digital transformational capabilities. Figure no. 6 presents digital transformation ranked by initiatives. The results is could lead us to believe that organizations are on track in their digital transformation, but if we dig into additional findings, the data show a distinct reality.

Figure no.6. Top ranked digital transformation initiatives (Deloitte, 2019)

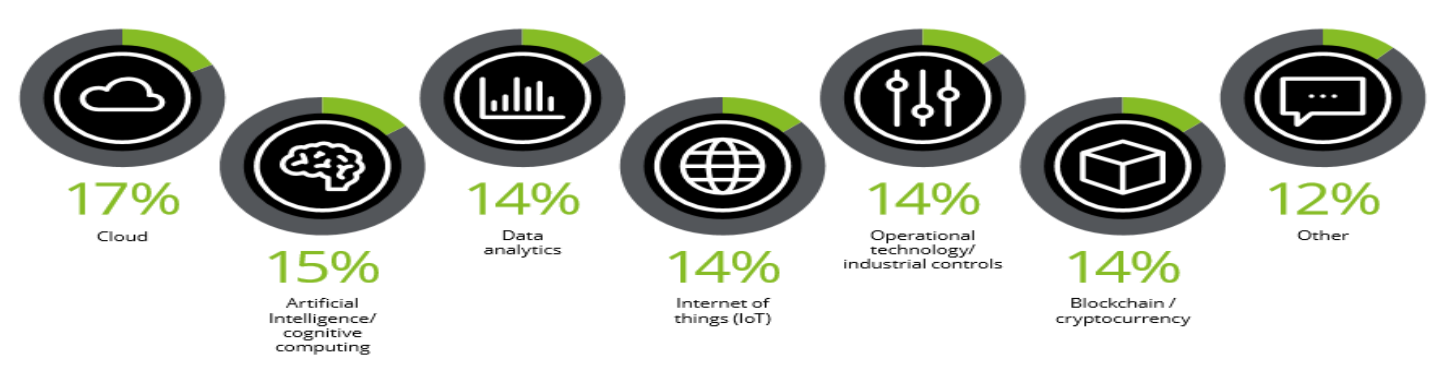

Cyber-attacks are a real threat. Today data become more valuable than money, gold, or stocks. Cyber-attack is a real threat and will increase in its intensity and sophistication in the coming years. Thus, the research underlined the importance of redesigning the organizational structure for any business, giving more attention to cyber security, and to employ specialized personal, able to identify and develop a solution for data security and cyber transformation.

So rapid are the developments, in fact, that while the digitization of everything has become a hallmark of tech's promise of individual and business empowerment (Muro, et.al., 2017; Moşteanu, 2020d; Moşteanu and Galea, 2020). In the digital age, organizations need to reinvent themselves at a structural level and to become suppler (Moşteanu, 2019b).

If years ago, digitalization was not a concern, currently a demand development for new skills and qualifications is an actual market outcome. The research finds out that the main challenges encountered in digitizing the activity of institutions came out from the redesigning of organizations structure which started to use actual technologies, and this entail developing and implementing an integrated approach of functions and responsibilities.

\section{Limitations and direction for future research}

The present research paper presents some limitations in terms of data related to the number of organizations which redesign their structure in order to integrate the new technologies in their business processes. The author intends to develop a further research, based on more detailed information and data correlated to the skills, competences, and activities required for developing and implementing digital systems in any organizational structures, as well as the reallocation and the requalification of employees.

\section{References}

Ayandibu, A.O., Houghton, J., 2017. The role of Small and Medium Scale Enterprise in local economic development (LED). Journal of Business and Retail Management Research, 11(2).

Beck, U., Giddens, A., \& Lash, S., 1994. Reflexive Modernization. Cambridge: Polity Press.

Azuly, D., 2019. Artificial Intelligence in Finance - a Comprehensive Overview. Retrieved November 15, 2019 from https://emerj.com/ai-sector-overviews/artificial-intelligence-in-finance-a-comprehensive-overview/

Brynjolfsson, E., 2011. ICT, innovation and the e-economy. EIB Papers, 16(2), 60-76.

Boulton, C., 2018. What is Digital Transformation? A Necessary Disruption. CIO. Retrieved in December 2018 from https://www.cio.com/article/3211428/digital-transformation/ what-is-digital-transformation-a-necessarydisruption.html.

Boutetiere, H., Reich, A., 2018. Unlocking Success in Digital Transformations. McKinsey Digital. Retrieved on November 20, 2019 from https://www.mckinsey.com/business-functions/organization/our-insights/unlocking-successin-digital-transformations

CISCO, 2019. What is cybersecurity? Retrieved on November 15, 2019, from 
https://www.cisco.com/c/en/us/products/security/what-is-cybersecurity.html

Dilek, S., Çakır, H., Aydın, M., 2015. Applications of artificial intelligence techniques to combating cybercrimes: A review. arXiv preprint arXiv:1502.03552

Deloitte, 2019. The future of cybersecurity survey 2019. Cyber everywhere. Succeed anywhere. Retrieved on February 21, 2020 from https://www2.deloitte.com/content/dam/Deloitte/us/Documents/finance/us-the-future-ofcyber-survey.pdf

European Commission, 2020. Digital Skills \& Jobs. Retrieved on February 20, 2020 from https://ec.europa.eu/digitalsingle-market/en/policies/digital-skills

European Commission, 2019. Digital Europe Programme; Summary Report on the targeted consultation on the future of investment in Europe's digital economy. Retrieved on, December 17, 2019 from https://ec.europa.eu/digitalsingle-market/en/news/digital-europe-programme-summary-report-targeted-consultation-future-investmenteuropes-digital

Hansen, L., Nissenbaum, H., 2009. Digital disaster, cyber security, and the Copenhagen School. International studies quarterly, 53(4), 1155-1175.

Jacobs, D.C., Yudken, J., 2003. The Internet, Organizational Change and Labor: The Challenge of Virtualization. Routledge.

Jones, G.R., 2013. Organizational theory, design, and change. Upper Saddle River, NJ: Pearson.

Marketingcharts, 2017. AI is the Marketing Trend That Has the Most Marketers Feeling Unprepared. Retrieved on November 17, 2019 from https://www.marketingcharts.com/customer-centric/analytics-automated-andmartech-81716

Maruti TechLabs, 2019. 5 ways AI is transforming the finance industry. Retrieved November 15, 2019 from https://www.marutitech.com/ways-ai-transforming-finance/

McCalman, J., Potter, D., 2015. Leading cultural change: The theory and practice of successful organizational transformation. Kogan Page Publishers.

McAfee, A., Brynjolfsson, E., 2017. Machine, Platform, Crowd: Harnessing Our Digital Future. WW Norton \& Company.

Moshirian, F., 2011. The global financial crisis and the evolution of markets, institutions and regulation. Journal of Banking \& Finance, 35(3), 502-511.

Moşteanu, N.R., 2019a. Principles of International Finance, Banking and Taxation. Publisher: Universitara, Bucuresti, Romania.

Moşteanu, N.R., 2019b. Intelligent Foreign Direct Investments to boost economic development - UAE case study. The Business \& Management Review, 10(2), 1-9.

Moşteanu, N.R., 2019c. International Financial Markets face to face with Artificial Intelligence and Digital Era. Theoretical and Applied Economics, 3(620), 123-133.

Moşteanu, N.R., Modarress Fathi, B., 2020. Financial Digitalization on jobs market structure. Presented at the 9th International Conference on Business and Economic Development (ICBED), 20-22 August 2020 New York, USA.

Moşteanu, N.R., 2020a. Management of Disaster and Business Continuity in a Digital World. International Journal of Management, 11(4), 169-177.

Moşteanu, N.R., 2020b. Artificial Intelligence and Cyber Security - A Shield against Cyberattack as a Risk Business Management Tool - Case of European Countries. Quality-Access to Success Journal, 21(175), 148-156.

Moşteanu, N.R., 2020c. Green Sustainable Regional Development and Digital Era. In Green Buildings and Renewable Energy (181-197).

Moşteanu, N.R., 2020d. Education, qualification awareness and social civism to build and sustain a healthy and developed society. Proceedings of $28^{\text {th }}$ European Biomass Conference \& Exhibition, EUBCE 2020, Marseille, France, 6-7 July 2020.

Moşteanu, N.R., 2020e. Socio-Financial Disruption - Key tips to manage and ensure the business continuity. Global Journal of Social Sciences Studies, 6(1). To be in July 2020.

Moşteanu, N.R., 2020f. Finance digitalization and its impact on labour market. Technium Social Sciences Journal, 8, 598605.

Moşteanu, N.R., Faccia, A., 2020. Digital Systems and New Challenges of Financial Management - FinTech, XBRL, Blockchain and Cryptocurrencies. Quality-Access to Success Journal, 21(174), 159-166.

Moşteanu, N.R., Galea, K., 2020. Artificial Intelligence and Cyber Security - face to face with Cyberattack - a Maltese case of Risk Management approach. EcoForum, 9(2), 672-679.

Moşteanu, N.R., Faccia, A., Cavaliere, L.P.L., 2020a. Digitalization and green economy - changes of business perspectives. In Proceedings of 4th International Conference on Cloud and Big Data Computing (ICCBDC), Liverpool, UK, August 26-28, 2020. 
Moşteanu, N.R., Faccia, A., Cavaliere, L.P.L., 2020b. Disaster Management - Digitalization and Financial Resources important factors to keep the organization ongoing. In Proceedings of 4 th International Conference on Cloud and Big Data Computing (ICCBDC), Liverpool, UK, August 26-28, 2020.

Moşteanu N.R., Faccia, A., Cavaliere, L.P.L., Bhatia, S., 2020c. Digital technologies' implementation within financial and banking system during socio distancing restrictions - back to the future, International Journal of Advanced Research in Engineering and Technology, 11(6). 307-315.

Murphey, D., 2019. A history of information security. Retrieved on November 15, 2019 from IFSEC Global website https://www.ifsecglobal.com/cyber-security/a-history-of-information-security/.

Muro, M., Liu, S., Whiton, J., Kulkarni, S., 2017. Digitalization and the American workforce. Think-Asia.

Nambisan, S., Wright, M., Feldman, M., 2019. The digital transformation of innovation and entrepreneurship: Progress, challenges and key themes. Research Policy, 48(8), 103773.

Oxford College of Marketing, 2016. Digital Disruption: What Is It and How Does It Impact Businesses? Retrieved on February 20, 2020 from https://blog.oxfordcollegeofmarketing.com/2016/02/22/what-is-digital-disruption/

Rogers, D.L., 2016. The digital transformation playbook: Rethink your business for the digital age. Columbia University Press.

Scardovi, C., 2017. Digital Transformation in Financial Services. Springer International Publishing. Retrieved from //www.springer.com/gp/book/9783319669441

Shiva, S., Roy, S., Dasgupta, D., 2010. Game theory for cyber security. In Proceedings of the Sixth Annual Workshop on Cyber Security and Information Intelligence Research (1-4).

Solis, B., Li, C., Szymanski, J., 2014. The 2014 State of Digital Transformation. Altimeter Group.

Venkatraman, V., 2017. The digital matrix: new rules for business transformation through technology. Greystone Books.

Vovchenko, N.G., Andreeva, A.V., Orobinskiy, A.S., Filippov, Y.M., 2017. Competitive advantages of financial transactions on the basis of the blockchain technology in digital economy. European Research Studies, 20(3B), 193.

Williamson, B., 2016. Digital education governance: data visualization, predictive analytics, and 'real-time' policy instruments. Journal of Education Policy, 31(2), 123-141.

Shiva, S., Roy, S., Dasgupta, D. Game theory for cyber security. In Proceedings of the 6th Annual Workshop on Cyber Security and Information Intelligence Research (34). ACM, 2010. 